\title{
Low-Temperature Coarsening and Plastic Flow Behavior of an Alpha/Beta Titanium Billet Material with an Ultrafine Microstructure
}

\author{
G.A. SARGENT, A.P. ZANE, P.N. FAGIN, A.K. GHOSH, and S.L. SEMIATIN
}

DOI: $10.1007 / \mathrm{s} 11661-008-9695-\mathrm{y}$

(c) The Minerals, Metals \& Materials Society and ASM International 2008

\section{Erratum to: METALLURGICAL AND MATERIALS TRANSACTIONS A DOI: 10.1007/s11661-008-9650-y}

THE correct affiliation for S.L. Semiatin is as follows:
Senior Scientist, Materials Processing/Processing Science, is with the Materials and Manufacturing Directorate, Air Force Research Laboratory, AFRL/RXLM, Wright-Patterson Air Force Base, OH 45433-7817.

G.A. SARGENT, Consultant, and P.N. FAGIN, Technologist, are with the Materials and Processes Division, UES, Inc., Dayton, $\mathrm{OH}$ 45432. Contact e-mail: gsargent@woh.rr.com A.P. ZANE, Undergraduate Student, is with Chemistry Department, Wright-State University, Dayton, $\mathrm{OH}$ 45435. A.K. GHOSH, Professor, is with the Materials Science and Engineering Department, University of Michigan, Ann Arbor, MI 48109-2136. S.L. SEMIATIN, Senior Scientist, Materials Processing/Processing Science, is with the Materials and Manufacturing Directorate, Air Force Research Laboratory, AFRL/ RXLM, Wright-Patterson Air Force Base, OH 45433-7817.

The online version of the original article can be found under doi: 10.1007/s11661-008-9650-y.

Article published online October 7, 2008 